\title{
Biochemical characterization of olive oil samples obtained from fruit mixtures and from oil blends of four cultivars grown in Central Tunisia
}

\author{
Meriem Tekaya ${ }^{1,{ }^{*}}$, Mguidich Belhaj Amel ${ }^{2}$, Beligh Mechri ${ }^{1}$, Mohamed Ayadi ${ }^{3}$, \\ Manel Ben Slamia Aouina ${ }^{4}$, Jalel Mkada ${ }^{4}$, Hajer Belkhiria ${ }^{2}$, Ahlem Guesmi ${ }^{5}$, Naoufel Ben Hamadi ${ }^{5}$, \\ Mohamed Hammami ${ }^{1}$, Guido Flamini ${ }^{6,7}{ }^{4}$ and Mouna Aïachi Mezghani ${ }^{2}$ \\ ${ }^{1}$ Biochemistry Laboratory, USCR "Mass Spectrometry", LR-NAFS /LR12ES05 "Nutrition-Functional Food and Vascular Health", \\ Faculty of Medicine, University of Monastir, Monastir, Tunisia \\ ${ }^{2}$ Research Laboratory, Durability of Oleiculture in Semi-Arid and Arid Regions, Amelioration of the Productivity of Olive Tree and \\ Quality of Products, Olive Tree Institute of Sousse, Ibn Khaldoun Street, B.P. 14, 4061 Sousse, Tunisia \\ ${ }^{3}$ Olive Tree Institute of Sfax, Airport Street, B.P. 1087, 3000 Sfax, Tunisia \\ ${ }^{4}$ Regional Commissary for Agricultural Development of Sousse, Alger Street, 4029 Sousse, Tunisia \\ ${ }^{5}$ Chemistry Department, College of Science, IMSIU (Imam Mohammad Ibn Saud Islamic University), Riyadh 11623, Kingdom of Saudi \\ Arabia \\ ${ }^{6}$ Dipartimento di Farmacia, Via Bonanno 6, 56126 Pisa, Italy \\ ${ }^{7}$ Centro Interdipartimentale di Ricerca "Nutraceutica Alimentazione per la Salute" Nutra Food, University of Pisa, Pisa, Italy
}

Received 30 September 2021 - Accepted 9 December 2021

\begin{abstract}
Blends of olive oils obtained from four cultivars (Olea europaea L. cv. Chemlali, Chetoui, Oueslati and Koroneiki) were produced by two different methods of blending: processing fruit mixtures or mixing monovarietal oils, using the same proportions of selected cultivars. The obtained blends were biochemically characterized to evaluate quality, and the two methods were compared. The results indicated that the most successful formulations are mainly F8 $(60 \%$ Chemlali $\times 20 \%$ Oueslati $\times 20 \%$ Koroneiki) characterized by the highest contents of phenols and an elevated oxidative stability, and F5 (50\% Chemlali $\times 50 \%$ Koroneiki) containing the highest MUFA level and the highest oxidative stability. The effect of the blending process on pigments and volatiles cannot be easily regulated, unlike phenols, fatty acid composition and OS, all of which positively correlated to the fruit mass ratio in the blend. Results suggest that processing fruit mixtures of different cultivars resulted in a better oil quality than that of oils obtained by the common oil blending method. This blending procedure offers a possibility to modulate the contents of antioxidants, fatty acids and volatile compounds in virgin olive oil, and therefore, its quality and sensorial characteristics.
\end{abstract}

Keywords: Olea europaea L. / blending / antioxidants / fatty acids / volatile compounds

Résumé - Caractérisation biochimique d'échantillons d'huile d'olive obtenus à partir de mélanges de fruits et de mélanges d'huiles de quatre cultivars cultivés dans le centre de la Tunisie. Quatre variétés d'olivier prospectées au centre de la Tunisie (Olea europaea L. cv. Chemlali, Chetoui, Oueslati et Koroneiki) ont fait l'objet d'un essai de mélanges variétaux par deux méthodes de coupage, en vert et en huile, tout en utilisant la Chemlali comme variété principale. La méthode classique de coupage à huile consiste à mélanger les huiles monovariétales de deux ou trois variétés à des proportions bien définies. Par contre, La méthode de coupage en vert consiste à mélanger les fruits de ces mêmes variétés avant leur broyage, et en extraire l'huile polyvariétale. Les mélanges obtenus ont été caractérisés biochimiquement pour évaluer la qualité. Les résultats ont indiqué qu'une meilleure qualité d'huile a été obtenue avec la méthode de coupage en vert. Les formulations les plus réussies sont principalement F8 (60\% Chemlali $\times 20 \%$ Oueslati $\times 20 \%$ Koroneiki) caractérisée par le contenu le plus élevé de phénols

\footnotetext{
*Correspondence: meriem_tekaya@yahoo.fr
} 
$(875,32 \mathrm{mg} / \mathrm{kg})$ et une stabilité oxydative élevée $(\mathrm{OS}=11,88 \mathrm{~h})$, et F5 $(50 \%$ Chemlali $\times 50 \%$ Koroneiki) contenant le niveau le plus élevé de MUFA (70,69\%) et l'OS la plus élevée (13,83 h). L'effet du coupage sur les pigments et les composés volatiles ne peut pas être facilement régulé, contrairement aux phénols, à la composition acidique et à l'OS, qui sont tous en corrélation positive avec le pourcentage des fruits de chaque variété dans le mélange. Cette procédure offre la possibilité de moduler les teneurs en antioxydants, en acides gras et en composés volatils dans l'huile d'olive, et donc sa qualité et ses caractéristiques sensorielles.

Mots clés : Olea europaea L. / coupage / antioxydants / acides gras / composes volatiles

\section{Introduction}

Olive oil is often the fat preferred by consumers who are conscious of the health benefits of the Mediterranean diet. The health benefits of olive oil are attributed to the high contents of oleic acid and other minor components, especially phenol derivatives. Oils rich in monounsaturated fatty acids (MUFAs) and poor in saturated fatty acids (SFAs) are favored because of the confirmed valuable effect of MUFAs on serum cholesterol levels (Preedy and Watson, 2010). It is well known that the consumption of certain natural antioxidants, in particular polyphenols, has several beneficial effects on health. These bioactive compounds have strong radical scavenging capacity and can play a key role in the protection against oxidative damages and cellular aging (Talhaoui et al., 2015). Besides of their bioactivity, phenols have a major role in the pungent and bitter taste of the oil and greatly improve its oxidative stability (Pedan et al., 2019).

The biological properties of olive oil are also associated to the occurrence of other minor components such as squalene and phytosterols, as well as $\alpha$-tocopherol and $\beta$-carotene which were reported to have an important role in preventing oxidation and could help to prolong the shelf-life of extra virgin olive oil (Jimenez-Lopez et al., 2020). Chlorophylls and carotenoids are the main pigments responsible for the distinctive color of the oil. More importantly, there is a renewed interest in these pigments in relation to the health benefits they may provide (Moyano et al., 2010).

Tunisian orchards are rich in several varieties, but they are dominated by two major ones: Chetoui in the North and Chemlali in the Centre and the South. Thus, it is necessary to conduct research on secondary cultivars in order to diversify Tunisian olive oil resources and enhance the quality.

Chemlali variety, although appreciated by many Tunisian consumers, contains high levels of palmitic and linoleic acids and low levels of monounsaturated fatty acids (especially oleic acid) and phenolic derivatives (Dabbou et al., 2009). These shortcomings could greatly limit Tunisian olive oil exportation, particularly in the existence of a very competitive international market that requires high quality. In addition, taking into consideration the health benefits of MUFA and minor compounds, particularly phenols and their effect on oxidative stability of the oils, there is a need to select an introduced cultivar that contributes to the enhancement of quality and health value of Chemlali oil by blending process. For this reason, Tunisia has encouraged the plantation of several Mediterranean varieties. In their origin areas of cultivation, these cultivars produce oils with different biochemical compositions and sensory profiles. Nevertheless, before using these new cultivars in blending process, their behavior in other sites must be evaluated. Indeed, the biochemical composition of olive oil, besides being strongly dependent on cultivar, is also affected by many other factors, essentially climatic and edaphic conditions (Ben Youssef et al., 2012).

Several studies have investigated the effect of the common method of oil blending on the final quality of Chemlali oil (Issaoui et al., 2009; Youssef et al., 2014). However, very few studies have been conducted on the effect of using the method of processing olive fruits of different cultivars on the final extracted oil. Reboredo-Rodríguez et al. (2015) observed that the olive co-crushing of four cultivars in different proportions clearly influenced the sensory property of the resulting oils. Angerosa and Basti (2003) compared only the volatile fraction of oil samples obtained by the two methods of blending using two cultivars.

In the current study, quality indices, pigment and phenolic concentrations, acidic and volatile profiles, as well as oxidative stability, were assessed with the aim: (i) to compare the biochemical compositions of the oils of these cultivars; (ii) to investigate the best combinations of blending that lead to a great improvement of the quality of Chemlali; (iii) to compare between the two methods of blending.

\section{Material and methods}

\subsection{Fruit sampling and blending program}

Fruits from 4 different Olea europaea L. cultivars, namely Chemlali, Chetoui, Oueslati and Koroneiki, grown in olive groves of central Tunisia (Sidi elHeni, governorate of Sousse), were harvested by hand, in December 2019. The quantity of olive fruits required for the virgin olive oil extraction was calculated previously based on the pre-established blending program. So, about $100 \mathrm{~kg}$ of Chemlali fruits and $35 \mathrm{~kg}$ of Chetoui, Oueslati and Koreneiki fruits were harvested. The maturity index (MI) of the fruits of each cultivar was determined according to the method described by Gutiérrez et al. (1999), which consists of the estimation of olive skin and pulp color. The four studied cultivars didn't have much different dynamics of fruit ripening. At the moment of sampling, Koroneiki, Chetoui, Chemlali and Oueslati had comparable maturity indices $(3.5,3.9,4.1$ and 4.3, respectively). Most of the fruits of Koreneiki and Chetoui had light violet epidermis, and most of the fruits of Chemlali and Oueslati had black epidermis.

The following program was conducted to prepare fruit samples:

a. Mixtures of olive fruits from two or three cultivars were prepared directly after harvest, with pre-established 
proportions $(20,40$ and $60 \%)$. Fruit blends were processed within $24 \mathrm{~h}$ of the olive harvest.

b. Monovarietal oils were also extracted within $24 \mathrm{~h}$ of the olive harvest.

c. Then, the same proportions of cultivars $(20,40$ and $60 \%)$ were used to prepare blends from oil mixtures of the same cultivars.

Taking into account variations in conditions in the common oil extraction practice, three independent repetitions were conducted for a single sample (of monovarietal oils and of fruit or oil combinations).

Chemlali is present in all blended oil samples as the main cultivar, at proportions of $50 \%$ and $60 \%$, the most used percentages of blending in commercial oils.

\subsection{Sample designations}

- From F1 to F8: oil samples obtained from processing fruit mixtures of two or three cultivars.

- From O1 to O8: oil samples obtained from monovarietal oil mixtures.

The following proportions of cultivars were established:

- bi-varietal blended oils: $\mathrm{F} 1$ and O1: 50\% Chemlali $\times 50 \%$ Chetoui; F2 and O2: $60 \%$ Chemlali $\times 40 \%$ Chetoui; F3 and O3: $50 \%$ Chemlali $\times 50 \%$ Oueslati; F4 and O4: $60 \%$ Chemlali $\times 40 \%$ Oueslati; F5 and O5: 50\% Chemlali $\times 50 \%$ Koroneiki; F6 and O6: 60\% Chemlali $\times 40 \%$ Koroneiki.

- Multivarietal blended oils: F7 and 07: 60\% Chemlali $\times 20 \%$ Chetoui $\times 20 \%$ Koroneiki; F8 and O8: $60 \%$ Chemlali $\times 20 \%$ Oueslati $\times 20 \%$ Koroneiki.

\subsection{Oil extraction procedure and blending process}

Olive oil was extracted using an Abencor system smallquantity mill, simulating commercial oil-extraction systems (MC2 Ingenierı Sistemas, Seville, Spain). Only healthy fruits were processed after removing leaves. These steps were followed in oil extraction: fruit crushing with a hammer mill $(1.5 \mathrm{~kg}$ ), malaxation of the paste (approximately $700 \mathrm{~g}$ ) for $30 \mathrm{~min}$ at $26 \pm 0.5^{\circ} \mathrm{C}$, and centrifugation in a two-phase decanter (3500 rpm over $1 \mathrm{~min}$, at room temperature). Malaxers are provided of a top cover to prevent the oxygen exposure and placed in the thermostated water bath. The extracted oil samples were filtered through the filter paper and stored in obscurity in fully filled and amber glass bottles until analyses.

Blending process was carried out carefully in a protected environment from oxidative damage. For each blend, a sample of $1.5 \mathrm{~L}$ was prepared; the appropriate amounts of monovarietal oils were transferred in a $2 \mathrm{~L}$ Erlenmeyer equipped with a magnetic stirrer (to ensure sample homogenization) and a nitrogen bubbling device. Bubbling and stirring were sustained for $15 \mathrm{~min}$. The obtained oil blend was then transferred into three $500 \mathrm{ml}$ fully filled amber glass bottles and saturated with nitrogen before hermetic closure. The blends were stored in obscurity at low room temperature $\left(18 \pm 1^{\circ} \mathrm{C}\right)$, until analyses.

\subsection{Physico-chemical and biochemical characterization of extracted oil samples}

Free fatty acidity and UV absorption coefficients $\left(\mathrm{K}_{232}\right.$ and $\mathrm{K}_{270}$ ) were determined following the methods described in the European Union Commission Regulation 2568/91.

Chlorophyll and carotenoid concentrations were analyzed following the method of Minguez-Mosquera et al. (1991). The chlorophyll content was determined at maximum absorption of $670 \mathrm{~nm}$, while the carotenoid fraction was quantified at $470 \mathrm{~nm}$.

Total phenols were extracted using methanol/Tween 20 mixture $(2 \% \mathrm{v} / \mathrm{w})$, and then colorimetrically quantified, according to the method of Montedoro et al. (1992) using the Folin-Ciocalteu reagent. The concentrations of total phenols were measured at $765 \mathrm{~nm}$ and values were expressed as mg of gallic acid per kilogram of oil.

Oleuropein aglycon and ligstroside aglycon are the most potent bitter tastants in olive oil (Cui et al., 2021) and have been shown to display antioxidant and free radical-scavenging activities. So, based on the polyphenol content, the bitterness intensity (IBe) can be estimated using the following equation (Beltrán et al., 2007):

$$
\begin{aligned}
I B e & =-7 \times 10^{-6} \times \text { Phenols }^{2}+0.0123 \times \text { Phenols } \\
& -0.8722 .
\end{aligned}
$$

The fatty acid analyses were carried out by gas chromatography (HP6890, Hewlet Packard Inc., USA) following the procedures described by Tekaya et al. (2016) using a method based on gas chromatography of the methyl esters of the fatty acids extracted with hexane. A standard fatty acid methyl ester reference mixture was used to identify the different peaks of fatty acids in each sample.

Oxidative stability was analyzed using a Rancimat apparatus (Mod. 743, Metrohm, Schweiz AG, Zofingen, Switzerland) with the method described by Tura et al. (2007). The Oxidation Stability Index (OSI) value is designated as the number of hours required for the rate of change in conductivity to reach a predetermined value.

Finally, the volatile fraction was sampled using Supelco SPME (solid-phase microextraction) and GC-MS analysis was performed following the method described by Ascrizzi et al. (2016).

\subsection{Statistical analysis}

Statistical analyses were conducted using the statistical package for social sciences (SPSS) program, release 11.0 for Windows (SPSS, Chicago, IL, USA). Values of measured parameters are shown as means \pm standard deviations $(n=3)$. Duncan's test was applied to identify significant differences among data. The statistical significance level was fixed at $\mathrm{p}<0.05$. 


\section{Results and discussion}

\subsection{Quality parameters}

All extracted oil samples are classified as "extra virgin olive oil" samples; values of acidity, $\mathrm{K}_{232}$ and $\mathrm{K}_{270}$ fell within the range of $0.8 \%, 2.50$ and 0.22 , respectively established for the highest quality category "extra virgin olive oil" (Regulation EC/1989/2003) (Tab. 1). As reported by several authors (Borges et al., 2016; Theodosi et al., 2021), these quality indices are basically affected by factors causing damage to the fruits (e.g., olive fly attacks or improper systems of harvesting, inconvenient conditions of transport and storage of olives) or to the oil (the processing technology and conditions of oil storage).

\subsection{Effects of the blending process on the content of pigments}

ANOVA test shows significant differences between the four cultivars $(\mathrm{P}<0.001)$ in pigment concentrations (Tab. 1). Chetoui is the least-pigmented oil (1.01 and $5.38 \mathrm{mg} \mathrm{kg}^{-1}$ of chlorophylls and carotenoids, respectively). In contrast, pigments in Chemlali, Oueslati and Koroneiki olive oils were much more abundant; Oueslati is characterized by the highest carotenoid content $(18.40 \mathrm{mg} / \mathrm{kg})$ while Koroneiki exhibits the highest content in chlorophylls $(5.78 \mathrm{mg} / \mathrm{kg})$. Previous studies reported that the concentration of pigments can vary significantly depending on the variety (or cultivar) (Omri et al., 2020), the fruits ripening degree (Hassine et al., 2021), the climate (Criado et al., 2008) and growing conditions (Bedbabis et al., 2015).

The blending process affected significantly the amounts of pigments according to the proportion of cultivar in the blended oil. Indeed, because of its low contents in pigments, blending with Chetoui oil lead to a sharp decrease of pigment concentration with respect to Chemlali olive oil (F1, O1, F2, O2). However, it seems that blending oils of different cultivars does not necessarily result in a cumulative effect of the constituents of their oils. In fact, blending Chemlali with Oueslati, two oils rich in carotenoids, resulted in a significant decrease of the carotenoid concentration in their final blends (F3, O3, F4, O4). On the other hand, blending with Koroneiki contributed to a significant increase in chlorophyll concentration of Chemlali oil, in F5 and F6 blends. From the above results, it can be concluded that it is rather difficult to produce a blended olive oil with predictable pigment content.

Comparing the two methods of blending, in general, the concentrations of chlorophylls and carotenoids were higher in oil samples obtained by processing blends of fruits than in those obtained by the oil mixing method. Among all tested blends, the combination F8 is the most pigmented oil, followed by $\mathrm{F} 6$.

\subsection{Variation of total phenol content and bitterness intensity following the proportion of cultivars and the method of blending}

As summarized in Table 1, comparing between monovarietal oils, statistical analysis revealed that Koroneiki had the lowest concentration of total phenols $(452.39 \mathrm{mg} / \mathrm{kg})$, while the difference between phenol contents in Chemlali, Chetoui and Oueslati oil samples was not significant. These results are in accordance with that reported by some authors about the great influence of olive cultivar on phenolic content in olive oil (Baiano et al., 2013). On the basis of the classification established by Montedoro et al. (1992), the three autochthonous cultivars (Chemlali, Chetoui and Oueslati) are characterized by high contents of phenolic compounds ( $>500 \mathrm{ppm})$. The introduced cultivar (Koroneiki) presented a medium concentration of phenols (200-500 ppm).

Regarding blended oil samples, since the contents of polyphenols in Chemlali, Chetoui and Oueslati oils are almost similar, and that of Koroneiki is relatively lower, mixtures between Chemlali and other oils from the three cultivars did not significantly improve the concentration of total phenols in the final blended oil. However, it is clearly observed that milling fruit blends from two or three cultivars contributed to the enhancement of the pool of phenolic compounds in the final blended oil in comparison to the initial amount $(p<0.001)$. In all oil samples obtained by fruit blending process, the amount of total phenols was much higher than in those obtained by the common oil blending method. In addition, the concentrations of total phenols in the final blended oils appeared to change proportionally to the relative amount of each monovarietal fruits in the blends. Phenolic concentration slowly increased with the proportion of Chetoui and Oueslati in the blend. It is also remarkable that by mixing Chemlali fruits with both Oueslati and Koroneiki ones, even at only $20 \%$ of each introduced cultivar, total phenol content underwent to about $50 \%$ of increase. Indeed, $\mathrm{F} 8$ is characterized by the highest phenolic content $(875.32 \mathrm{mg} / \mathrm{kg})$, followed by F1 (about 35\% of increase) and F2 (about $31.3 \%$ of increase).

Bitterness is considered a positive sensory characteristic of olive oil and is often attributed to the presence of phenolic derivatives. By considering the phenol content, the bitterness intensity (IBe) can be predicted and oils can be categorized into different groups as suggested by Beltrán et al., 2007. Thus, in the current work, all the studied olive oil samples (monovarietal and blended oils) should be considered as very bitter oils ( $\mathrm{IBe}>3)$.

From a commercial point of view, because of their high levels of phenolic compounds, the obtained blended oils had the disadvantage to be too bitter, characteristics which might be not accepted by some consumers (Beltrán et al., 2007). From a health point of view, these oils are characterized by a high health value due to the bioactive properties of these derivatives.

\subsection{Changes in fatty acid composition}

Regarding the fatty acid methyl esters (FAMEs) composition, Koroneiki is distinguished by an interesting acidic profile (Tab. 2) with the highest proportion of monounsaturated fatty acids (MUFA; 77.55\%) and the lowest level of polyunsaturated fatty acids (PUFA; 7.82\%) because of its elevated oleic acid content $(\mathrm{C} 18: 1 ; 76.32 \%)$ and low linoleic acid content (C18:2; $6.69 \%$ ). Consequently, the ratio MUFA/PUFA, which is of great importance for its effects on the health properties of olive 


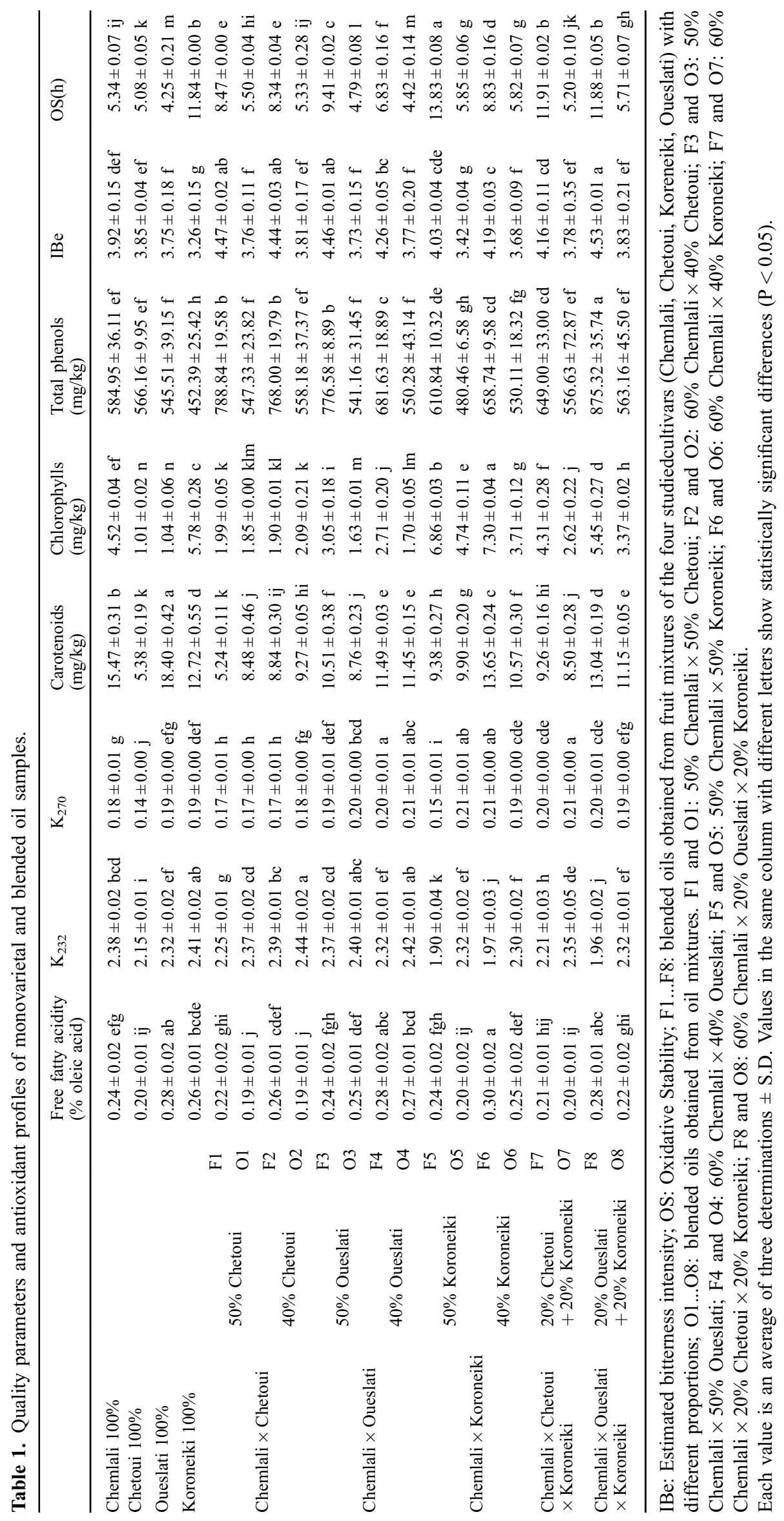




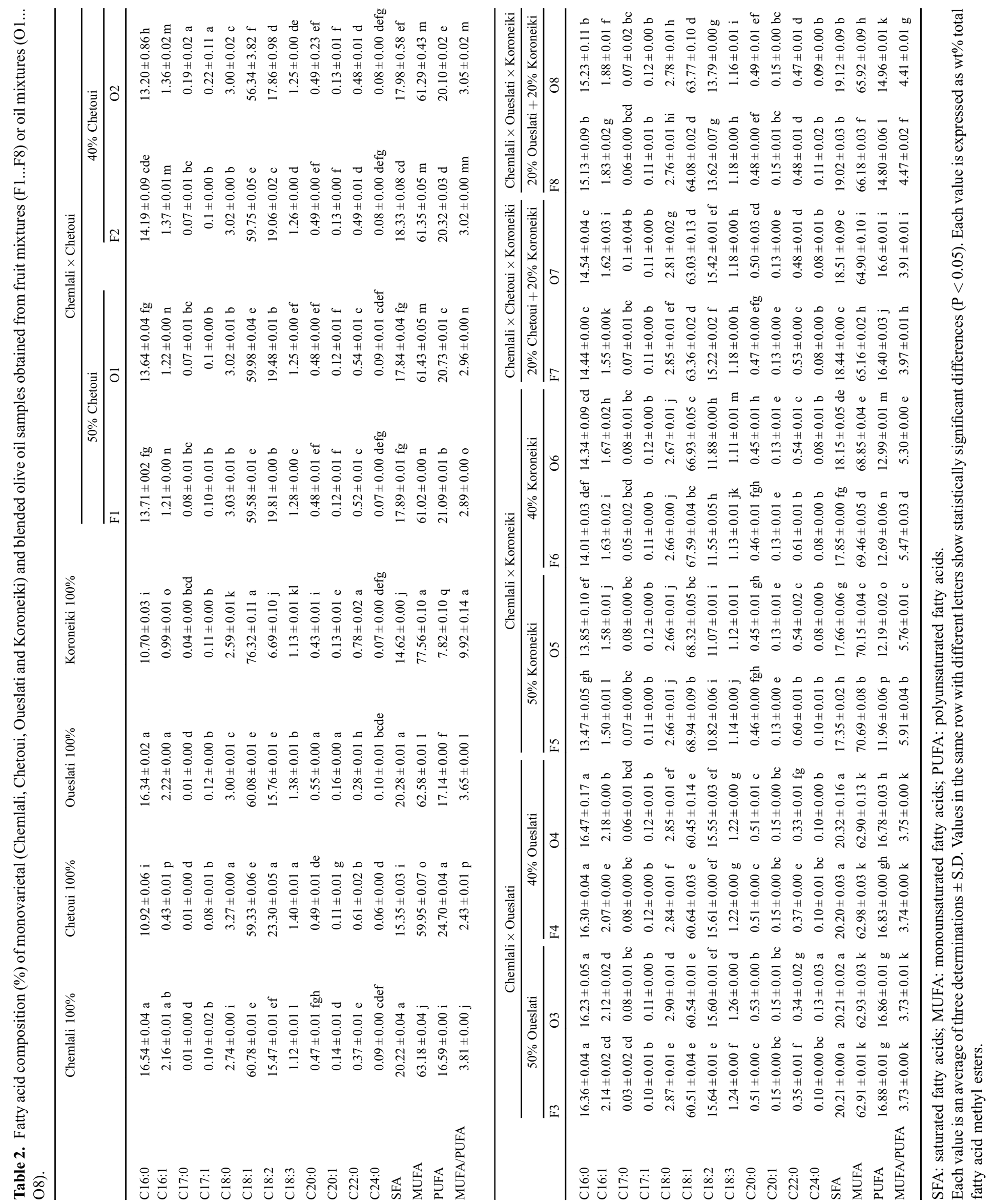


oils (Dag et al., 2011), is high (9.92). In addition, Koroneiki produces an oil with a relatively low level of palmitic acid (C16:0; 10.70\%) and saturated fatty acids (SFA; 14.62\%).

On the other hand, Chetoui, cultivated in central Tunisia, produced oil with low MUFA and C18:1 levels (59.95\% and $59.33 \%$, respectively) and high levels of PUFA, especially C18:2 (24.70\% and 23.30\% respectively). C18:2 level exceeds the value reported as a maximum limit in Reg. UE 2019/1604 $(21.0 \%)$. This is may be caused by agronomic and genetic factors. In fact, Chetoui cultivar has been reported to have a low genetic plasticity (Ben Youssef et al., 2012); it showed significant differences in oil quality parameters, including linoleic acid content, when the olive trees were cultivated away from the original plantation site (in the north of the country).

The ratio MUFA/PUFA is consequently very low (2.43). Oueslati oil is characterized by relatively low levels of oleic acid (about 60\%) and MUFA and high levels of palmitic acid, SFA and PUFA. Regarding Chemlali, this cultivar produces a virgin oil characterized by high levels of palmitic acid (16.54\%) and SFA (20.22\%), and relatively low levels of oleic acid $(60.78 \%)$ and MUFA (63.18\%). As observed in previous studies (Baccouri et al., 2007), Chemlali olive oil (especially Chemlali from Sfax) is characterized by a low level of oleic acid $(53 \%)$ and a high level of palmitic acid $(20 \%)$. Thus, we suggest that, when grown in central Tunisia, Chemlali produces virgin oil with a relatively improved fatty acid profile compared to that produced by the same cultivars grown in the South of Tunisia. Taking into consideration the health benefits of MUFA, especially oleic acid, and their effect on oxidative stability of the oils, there is a need to select an introduced cultivar that contributes to the enhancement of quality and the concentrations of bioactive compounds in Chemlali oil by blending process. As shown in Table 2, blending with Koroneiki oil was the most effective to enhance the levels of oleic acid and MUFA and to reduce the levels of SFA, especially palmitic acid, as well as PUFA, comparing to those in pure Chemlali oil. In fact, at $40 \%$ blending with Koroneiki olive oil, oleic acid increased by $10.12 \%$ using the method of oil mixtures (O6) and by $11.20 \%$ using the method of fruit mixtures (F6). At 50\% blending, it increased by $12.40 \%$ (in O5, oil mixture method) and by $13.42 \%$ (in F5, method of fruit mixtures). In parallel, palmitic acid underwent a significant decrease to $14.34 \%$ in $\mathrm{O} 6$ and to $14.01 \%$ in $\mathrm{F} 6$, at $40 \%$ blending. When the proportion of Koroneiki increases in the blended oil (at 50\%), C16:0 was further reduced to $13.85 \%$ in $\mathrm{O} 5$ and to $13.47 \%$ in F5. Hence, the four bi-varietal blended oils showed improved fatty acid compositions with respect to that of pure Chemlali oil; they are characterized by the highest MUFA content and the lowest SFA and PUFA levels, which lead to a significant amelioration of the ratio MUFA/PUFA, suggesting the enhancement of stability to oxidation of the oil.

Blending with Chetoui oil (which is characterized by reduced palmitic acid and SFA levels along with low oleic acid and MUFA levels and elevated linoleic acid and PUFA levels), caused a significant decrease of C16:0 and SFA of Chemlali oil; however, PUFA and C18:2 exhibit sharp increases compared to the initial concentrations in Chemlali oil, while MUFA and C18:1 levels underwent a significant reduction.

Oueslati oil has an acidic profile quite close to that of Chemlali oil. Thus, blends of Chemlali and Oueslati did not show important modifications in fatty acid levels compared to pure Chemlali oil.

Regarding the multivarietal blends (F7 and F8), when investigating the acidic profiles, it is evident that the concentrations of fatty acids in the final blended oils are proportionally related to the relative percentage of each monovarietal oils or fruits in the mixtures. The presence of Koroneiki, even at only $20 \%$ in these oils, contributed to a significant improvement of the acidic profile of Chemlali oil, despite the presence of Chetoui and Oueslati (with relatively modest acidic profiles) in the same proportion (20\%).

Comparing between the two methods of blending, in general, the two procedures did not significantly modify the fatty acid composition of the resulting olive oils, except for some changes that essentially affect blends of Chemlali with Koroneiki and Chetoui, which lead to changes in MUFA and PUFA levels. Interestingly, for all blends containing Koroneiki, the method of fruit mixing (F5, F6, F7 and F8) resulted in better quality of the oils in terms of richness in MUFA and an elevated ratio MUFA/PUFA. The assemblage F5 (50\% Chemlali $\times 50 \%$ Koroneiki) appeared to be the most successful formulation due to its higher content of MUFA (especially C18:1) and to its lower content of SFA and PUFA (especially $\mathrm{C} 18: 2$ ), leading to the enhancement of the ratio MUFA/PUFA. The above results demonstrated that the levels of fatty acids in the oil samples are positively correlated to the fruit mass ratio of the cultivars, which is in agreement with a previous work of Reboredo-Rodríguez et al. (2015).

These results suggest that the milling of fruits of different cultivars having different enzymatic activities did not cause any synergetic or antagonistic effect on the endogenous enzymes of each cultivar. Therefore, the fatty acid levels may be easily estimated in the oil obtained by the method of fruit blending.

\subsection{Effects of blending on oxidative stability of oil samples}

Oxidative stability (OS), measured by the Rancimat test at $120^{\circ} \mathrm{C}$, is a key parameter that contributes to the evaluation of olive oil quality. The results of the current study showed that this parameter depends essentially on the variety $(\mathrm{p}<0.05)$. Table 1 shows that Koroneiki oil had the highest induction time, with an average of $11.84 \mathrm{~h}$, followed by Chemlali oil $(5.34 \mathrm{~h})$. Oueslati had the lowest OS.

Using the common method of oil blending, the OS of Chemlali did not show a significant modification when blended with Chetoui oil. As expected, it decreased significantly when blended with Oueslati, because of the reduced OS of Oueslati oil. On the other hand, the OS of blends of Chemlali and Koroneiki exhibited a slight increase compared to that of pure Chemlali. Nevertheless, as observed for total phenols, oxidative stability of all oil samples obtained with the fruit blending process was significantly better than stability of samples obtained by the classic oil mixing method. Indeed, the procedure of fruit mixing allowed obtaining different blends with remarkably improved OS. The highest increase of OS (more than two-fold) was observed at $50 \%$ of blending with Koroneiki (assemblage F5). A very significant enhancement in Chemlali oil stability was observed using small proportions 
M. Tekaya et al.: OCL 2022, 29, 5

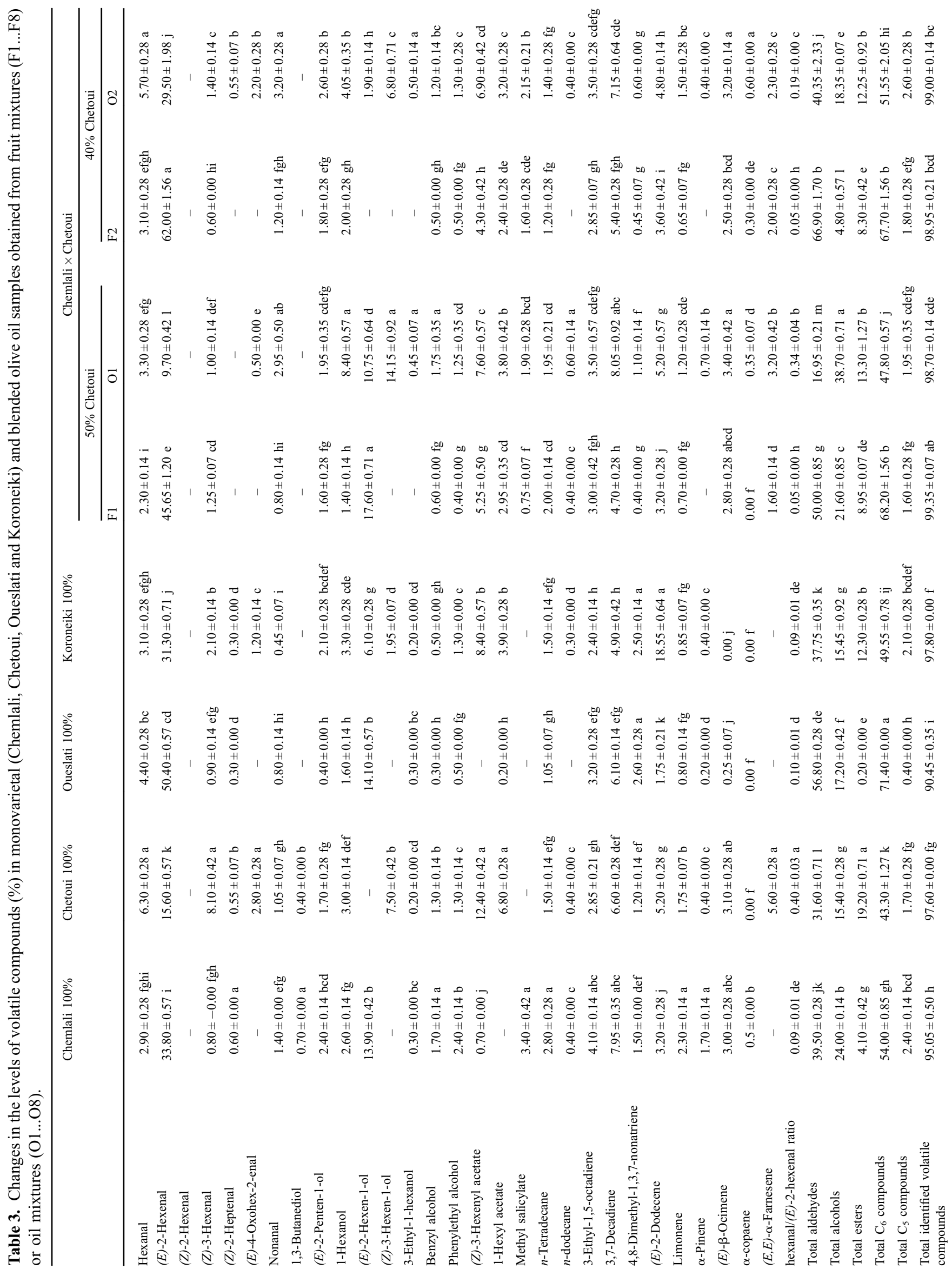


M. Tekaya et al.: OCL 2022, 29, 5

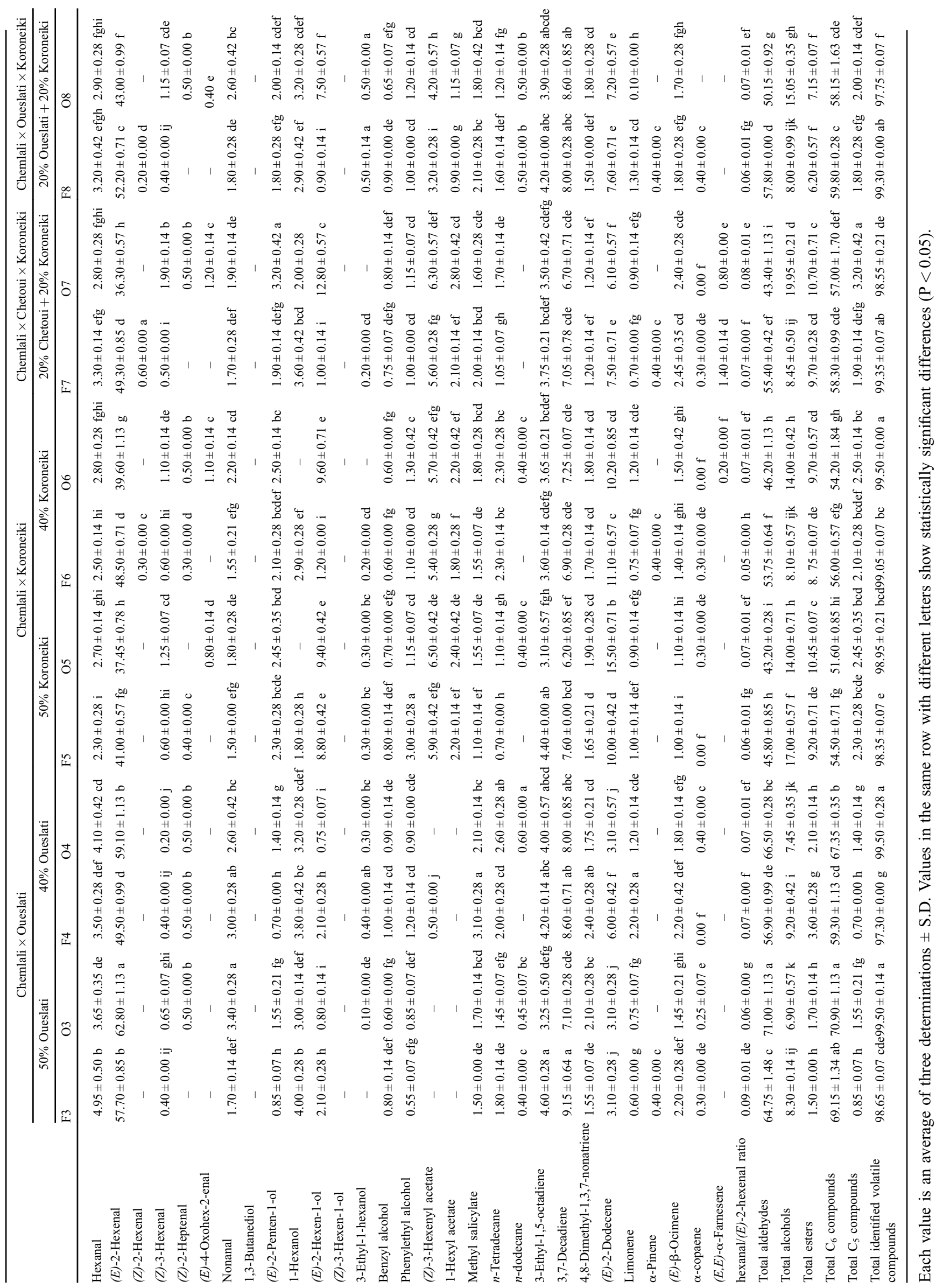


$(20 \%)$ of introduced cultivars: OS of Chemlali oil increased from $5.34 \mathrm{~h}$ to $11.91 \mathrm{~h}$ in F7 and to $11.88 \mathrm{~h}$ in F8.

Indeed, Koroneiki oil, despite the lowest phenols content, was characterized by the best OS; this may be due to its interesting fatty acid profile, with high levels of oleic acid and MUFA, and low levels of palmitic acid and SFA. In the same way, for blended oil samples, F5 oil had the highest OS due to its richness in MUFA (especially oleic acid) and its low content in PUFA and SFA. On the other hand, the high OS of F8 may be attributed to its richness in phenolic compounds.

\subsection{Changes in the volatile profile}

The volatile compounds produced during and after oil extraction contribute to the distinctive flavor of olive oil. The overall GC-MS measurement results are illustrated in Table 3. Twenty-nine compounds were characterized, representing $90.45-99.50 \%$ of the total spontaneously emitted volatile compounds (as \% of total peak area).

The most important group that contributes to aroma of olive oil was constituted by aldehydes, with $16.95-71 \%$ of the total emission, followed by alcohols (4.80-38.70\%) and esters (0.20-19.20\%). The main volatiles responsible for odour notes of high quality virgin olive oils are the $C_{6}(43.30-71.40 \%)$ and the $C_{5}(0.40-3.20 \%)$ volatile compounds produced from primary or secondary lipoxygenase (LOX) pathway, respectively (Angerosa, 2002). Based on the classification of Morales and Aparicio (1999), the major volatile compounds which contribute to the positive attributes of olive oil can be divided into three groups according to their sensory perceptions: hexanal, and hexyl acetate are responsible for the green-sweet aspect of the global green flavor (desirable perceptions). The second group, represented by (Z)-3-hexenal, (Z)-3-hexenol, and $(Z)$-3-hexenyl acetate, is responsible for the main green perception. Concerning the bitter-astringent aspect, the third group, it is represented by $(E)$-2-hexenal and $(E)$-2-hexen-1-ol.

Comparing the four olive cultivars, harvested at the same date and grown under the same pedoclimatic conditions, it can be observed that the genetic store of each variety, as well as the level and activity of enzymes involved in the LOX pathway, affect considerably the biosynthesis of each volatile compound in monovarietal oils, as also suggested by previous investigations (Angerosa, 2002; Angerosa and Basti, 2003). The total identified volatile compounds in Chemlali oil were $95.05 \%$; this content was significantly improved under the effect of blending process, in all blended oils. It seems that some interactions and/or synergisms could take place among the enzymes involved in the LOX cascade. When more cultivars are mixed, the enzymes involved in the LOX pathway may interact differently (synergic, additive, or antagonistic interactions) in their new environment, the olive paste, depending on the new contents of the fatty acid precursors of volatile compounds.

From a qualitative point of view, the contents of total volatiles differ significantly between monovarietal and multivarietal oils (Tab. 3). It is noticeable that the proportions of $\mathrm{C}_{6}$ are higher than those of $\mathrm{C}_{5}$ compounds in all the analyzed oils. Oueslati oil is distinguished by its high level of total $\mathrm{C}_{6}$ compounds $(71.40 \%)$ compared to Chemlali $(54.00 \%)$, Chetoui (43.30\%) and Koroneiki (49.55\%).
Using the method of oil blending, the concentration of the total $\mathrm{C}_{6}$ compounds seem to vary in a way proportional to the percentage of each monovarietal oil in the final blend, except for the blend O7, where the final concentration is significantly higher than in Chemlali, Chetoui and Koroneiki oils. Due to its richness in $\mathrm{C}_{6}$ compounds, the Oueslati oil contributed to a significant increase of the level of these derivatives when added to Chemlali oil (blends $\mathrm{O} 3$ and O4). Instead, the changes observed in the total $\mathrm{C}_{6}$ compounds in oils obtained by processing mixtures of fruits from 2 or 3 corresponding cultivars were not strictly dependent on the percentage of each cultivar in the mixture.

When classifying the volatile compounds on the basis of their chemical classes, it appears that Oueslati oil exhibited high levels of aldehydes $(56.80 \%)$ and especially (E)-2-hexenal $(50.40 \%)$ which confers "green" aroma or "fresh cut grass" (Kalua et al., 2007). Chetoui oil has the lowest level of $(E)$-2-hexenal $(15.60 \%)$. On the other hand, the total ester level (sum of (Z)-3-hexenyl acetate and 1-hexyl acetate) showed an opposite trend with respect to total aldehydes, and was present in high amount in Chetoui oil $(19.20 \%)$, but in trace amounts in Oueslati oil. Volatile esters contribute to the good flavor (fruity, sweet, green leaves) appreciated by consumers. Alcohol-acyl-transferases is the key enzyme involved in the biosynthesis of volatile esters; it catalyses esterification of an acyl moiety from an acylcoenzyme A (acyl-CoA) donor on to an alcohol (Goulet et al., 2015). Thus, we suggest that for Chetoui fruits, alcohol-acyltransferase activity might be higher than that of other cultivars, which possibly enhanced (Z)-3-hexenyl acetate and 1-hexyl acetate biosynthesis, and confer a unique flavor to Chetoui oil. Concerning volatile alcohols, Chemlali oil has the highest content compared to the other studied cultivars. This may be due to the differential activity of the enzymes involved in the biosynthesis of these compounds.

Blending process affected differently the contents of these classes of volatile compounds. Except for O1 and O2, all the blended oils showed a striking accumulation of aldehydes, especially (E)-2-hexenal, which reached the maximum concentrations in F2 and $\mathrm{O} 3$ blended oils.

In high quality oils, (E)-2-hexenal level should be higher than that of hexanal. After induction of oil oxidation, hexanal, an unpleasant-tasting aldehyde, rapidly increases in parallel with the decrease of $(E)$-2-hexenal level, which lead to the development of the "rancid'off-flavour". Thus, as suggested by Jiménez et al. (2007), lower hexanal/(E)-2-hexenal ratio is a sign of a better quality and lower oxidation degree of the oil. In our study, all blended oils showed very low hexanal/ (E)-2-hexenal ratio due to the low hexanal content and the high levels of $(E)$-2-hexenal. This indicates that no oxidation occurred after the blending process.

(E)-2-heptenal and nonanal have been associated with the oxidative status of virgin olive oil (Morales et al., 1997). Chemlali oil had the highest levels of these two compounds, while Koroneiki and Oueslati had the lowest.

Total alcohols decreased drastically in all blended oils compared to pure Chemlali (except in O1 oil sample). However, the trend of each alcohol compound is different among samples and there is no strict dependence between the percentage of cultivar in the fruit or oil mixtures and the final concentration of volatile compound in the corresponding 
blended oils. This confirms the existence of synergistic or antagonistic phenomena, especially for fruit mixtures, as already observed in previous studies (Angerosa and Basti, 2003; Reboredo-Rodríguez et al., 2015). These interactions and synergisms are probably due to the changed activity of the enzymes involved in the synthesis of volatile compounds in the olive paste, caused by the changed concentrations of each enzyme and of fatty acid precursors (linoleic and linolenic acids) (Reboredo-Rodríguez et al., 2015).

(E)-2-hexen-1-ol, the main alcohol derivative in the oil samples, is characterized by a green odor and by an unpleasant astringent-bitter taste (Aparicio et al., 1996). The level of this volatile was high in Chemlali and Oueslati oils, whereas it was low in Koroneiki and absent in Chetoui oil. The concentration of $(E)$-2-hexen-1-ol decreased significantly in all the blended oils, with the exception of F1.

Total esters appeared to change in a way proportional to the percent of each cultivar in the final blended samples, either produced from fruit mixtures or oil mixtures. The percentage of volatile esters can be simply estimated, since it is proportional to the mass ratio of the components in blended oils. When fruits or oil of the Chetoui cultivar are combined with those of Chemlali, the final blended oil shows a significantly higher ester concentration than that of pure Chemlali.

In this study, 5 terpene hydrocarbons were identified: three monoterpenes, Limonene, $\alpha$-Pinene, $(E)$ - $\beta$-Ocimene and two sesquiterpenes, $\alpha$-Copaene and $(E, E)-\alpha$-Farnesene. Comparing the four studied cultivars, Chemlali has the highest contents in the mentioned terpene compounds, except $(E, E)$ - $\alpha$-Farnesene, which was absent in Chemlali oil but present only in Chetoui oil and all the blended oils that contain Chetoui as introduced cultivar. (E)- $\beta$-Ocimene is absent in Koroneiki, but present in Tunisian cultivars. Our results are in agreement with those of Cecchi and Alfei (2013), who reported that terpene hydrocarbons are significantly affected by the olive variety.

Taken together, the current study proved that the volatile composition changes qualitatively and quantitatively when fruits or oil of Chemlali cultivar are combined with those of Chetoui, Oueslati and Koroneiki. The blending process could modify the concentrations of some aromatic compounds responsible for the distinctive flavour notes of olive oil, and therefore can change its sensorial quality. However as observed in the present study, the concentrations of volatile compounds in the final blended oil were not strictly dependent on the percentage of each cultivar in the mixture. Thus, the average amount of each compound cannot be easily calculated a priori, even if the average volatile composition of monovarietal oils is known.

\subsection{Selection of best formulations in terms of oil quality}

The results showed that the most successful formulations are mainly F8 and F5 blends. F8 although containing only $20 \%$ of the introduced cultivars (Koroneiki and Oueslati) was characterized by a high oxidative stability and the highest contents of phenols, as well as an interesting acidic profile. Blending Chemlali with Koroneiki at 50\% (in F5) leads to a significant improvement of MUFA level, especially C18:1, with a significant enhancement of stability to oxidation. The resulted blended oils are characterized by an increased level of total aroma compounds compared to pure Chemlali, due to increased amounts of total aldehydes and esters.

\section{Conclusion}

All the data obtained in this investigation agree to indicate that oils obtained by processing mixtures of fruits from two or three cultivars at the same time resulted in a better oil quality and elevated bioactive compound contents compared to that of each of the cultivars involved, or to that of oils obtained by the common oil blending method. At the moment of processing, Koroneiki, Chetoui, Chemlali and Oueslati had comparable maturity indices $(3.5,3.9,4.4$ and 4.5 , respectively) (Data not shown). Therefore, the studied cultivars didn't have much different dynamics of fruit ripening. Nevertheless, in local production practice, most cultivars are habitually harvested contemporaneously and processed as fruit mixtures, regardless of their different stages of ripeness.

Results suggest that this blending procedure offers a possibility to modulate the contents of antioxidants, fatty acids and volatile compounds in virgin olive oil, and therefore, its quality and sensorial characteristics. The assumption of possible interactions and/or synergisms in the production of volatile compounds from the LOX pathway was suggested. Each cultivar could have provided its particular enzymatic package, and some synergetic or antagonistic interactions have occurred in their new environment, the olive paste. Consequently, these interactions could affect the synthesis and accumulation of biochemical compounds in the resulting oil.

Acknowledgements. This project is carried out under the project VRR untitled "Gestion innovante et Plateforme cartographique de l'oléiculture dans le cadre de la stratégie Nationale (GESTPLATOLEA)" and under the MOBIDOC scheme, funded by the EU through the EMORI program and managed by the ANPR.

Conflicts of interest. The authors declare that they have no conflicts of interest in relation to this article.

\section{References}

Angerosa F. 2002. Influence of volatile compounds on virgin olive oil quality evaluated by analytical approaches and sensor panels. Eur J Lipid Sci Technol 104(9-10): 639-660. https://doi.org/10.1002/ 1438-9312(200210)104:9/10<639::AID-EJLT639>3.0.CO;2-U.

Angerosa F, Basti C. 2003. The volatile composition of samples from the blend of monovarietal olive oils and from the processing of mixtures of olive fruits. Eur J Lipid Sci Technol. https://doi.org/ 10.1002/ejlt.200390069.

Aparicio R, Morales MT, Alonso MV. 1996. Relationship between volatile compounds and sensory attributes of olive oils by the sensory wheel. J Am Oil Chem Soc 73: 1253-1264. https://doi. org/10.1007/BF02525454.

Ascrizzi R, Amadei L, Cioni PL, Flamini G, Pisa U, Bonanno V. 2016. Geographical patterns of in vivo spontaneously emitted volatile organic compounds in Salvia spp. Microchem $J$ 133: 13-21. https://doi.org/10.1016/j.microc.2017.03.002. 
Baccouri B, Ben Temime S, Taamalli W, Daoud D, M'Sallem M, Zarrouk M. 2007. Analytical characteristics of virgin olive oils from two new varieties obtained by controlled crossing on meski variety. J Food Lipids 14(1): 19-34. https://doi.org/10.1111/ j.1745-4522.2006.00067.x.

Baiano A, Terracone C, Viggiani I, Del Nobile MA. 2013. Effects of cultivars and location on quality, phenolic content and antioxidant activity of extra-virgin olive oils. JAOCS - J Am Oil Chem Soc 90: 103-111. https://doi.org/10.1007/s11746-012-2141-8.

Bedbabis S, Trigui D, Ben Ahmed C, et al. 2015. Long-terms effects of irrigation with treated municipal wastewater on soil, yield and olive oil quality. Agric Water Manage 160: 14-21. https://doi.org/ 10.1016/j.agwat.2015.06.023.

Beltrán G, Ruano MT, Jiménez A, Uceda M, Aguilera MP. 2007. Evaluation of virgin olive oil bitterness by total phenol content analysis. Eur J Lipid Sci Technol. https://doi.org/10.1002/ ejlt.200600231.

Ben Youssef N, Leilla A, Youssef O, et al. 2012. Influence of the site of cultivation on Chétoui olive (Olea europaea L.) oil quality. Plant Prod Sci. https://doi.org/10.1626/pps.15.228.

Borges TH, Pereira JA, Cabrera-vique C, Lara L, Oliveira AF, Seiquer I. 2016. Characterization of Arbequina virgin olive oils produced in different regions of Brazil and Spain: Physicochemical properties, oxidative stability and fatty acid profile. Food Chem. https://doi.org/10.1016/j.foodchem.2016.07.162.

Cecchi T, Alfei B. 2013. Volatile profiles of Italian monovarietal extra virgin olive oils via HS-SPME-GC-MS: Newly identified compounds, flavors molecular markers, and terpenic profile. Food Chem 141(3): 2025-35. https://doi.org/10.1016/j.food chem.2013.05.090.

Criado MN, Romero MP, Casanovas M, Motilva MJ. 2008. Pigment profile and colour of monovarietal virgin olive oils from Arbequina cultivar obtained during two consecutive crop seasons. Food Chem. https://doi.org/10.1016/j.foodchem.2008.02.075.

Cui M, Chen B, Xu K, et al. 2021. Activation of specific bitter taste receptors by olive oil phenolics and secoiridoids. Sci Rep 11: 22340.

Dabbou S, Issaoui M, Servili M, et al. 2009. Characterisation of virgin olive oils from European olive cultivars introduced in Tunisia. Eur J Lipid Sci Technol. https://doi.org/10.1002/ejlt.200800032.

Dag A, Kerem Z, Yogev N, Zipori I, Lavee S, Ben-David E. 2011. Influence of time of harvest and maturity index on olive oil yield and quality. Sci Hortic 127(3): 358-366. https://doi.org/10.1016/j. scienta.2010.11.008.

Goulet C, Kamiyoshihara Y, Lam NB, et al. 2015. Divergence in the enzymatic activities of a tomato and solanum pennellii alcohol acyltransferase impacts fruit volatile ester composition. Mol Plant 8: 153-162. https://doi.org/10.1016/j.molp.2014.11.007.

Gutiérrez F, Jímenez B, Ruíz A, Albi MA. 1999. Effect of olive ripeness on the oxidative stability of virgin olive oil extracted from the varieties Picual and Hojiblanca and on the different components involved. J Agric Food Chem 47: 121-127.

Hassine KBBEN, Mnif W, Smaoui S, Dhaouadi S, Aichi H, Ben M. 2021. Virgin olive oil quality in relation to olive ripening stage and malaxation temperature. Agric Biotechnol 82(6): 4781-4788.

Issaoui M, Flamini G, Ben Hassine $\mathrm{K}$, Chehab $\mathrm{H}$, Brahmi $\mathrm{F}$, Hammami M. 2009. Improvement of Chemlali olive oil oxidative stability by blending with Chétoui and Rekhami cultivars. Int J Food Sci Technol. https://doi.org/10.1111/ j.1365-2621.2009.01961.x.

Jiménez A, Beltrán G, Uceda M. 2007. High-power ultrasound in olive paste pretreatment. Effect on process yield and virgin olive oil characteristics. Ultrason Sonochem 14(6): 725-31. https://doi. org/10.1016/j.ultsonch.2006.12.006.

Jimenez-Lopez C, Carpena M, Lourenço-Lopes C, et al. 2020. Olive oil.

Kalua CM, Allen MS, Bedgood DR, Bishop AG, Prenzler PD, Robards K. 2007. Olive oil volatile compounds, flavour development and quality: A critical review. Food Chem 100: 273-286. https://doi.org/10.1016/j.foodchem.2005.09.059.

Minguez-Mosquera MI, Rejano-Navarro L, Gandul-Rojas B, Sanchez Gomez AH, Garrido-Fernandez J. 1991. Color-pigment correlation in virgin olive oil. J Am Oil Chem Soc. https://doi.org/ 10.1007/BF02657688.

Montedoro G, Servili M, Baldioli M, Miniati E. 1992. Simple and hydrolyzable phenolic compounds in virgin olive oil. 1. Their extraction, separation, and quantitative and semiquantitative evaluation by HPLC. J Agric Food Chem. https://doi.org/ 10.1021/jf00021a019.

Morales MT, Aparicio R. 1999. Effect of extraction conditions on sensory quality of virgin olive oil. JAOCS - J Am Oil Chem Soc. https://doi.org/10.1007/s11746-999-0234-9.

Morales MT, Rios JJ, Aparicio R. 1997. Changes in the volatile composition of virgin olive oil during oxidation: flavors and offflavors. J Agric Food Chem 45: 2666-2673. https://doi.org/ 10.1021/jf960585+.

Moyano MJ, Heredia FJ, Meléndez-Martínez AJ. 2010. The color of olive oils: The pigments and their likely health benefits and visual and instrumental methods of analysis. Compr Rev Food Sci Food Saf 9: 278-291. https://doi.org/10.1111/j.1541-4337.2010.00109. $\mathrm{x}$.

Omri A, Abdelhamid S, Ayadi M, et al. 2020. The investigation of minor and rare Tunisian olive cultivars to enrich and diversify the olive genetic resources of the country. J Food Compos Anal 95: 103657. https://doi.org/10.1016/j.jfca.2020.103657.

Pedan V, Popp M, Rohn S, Nyfeler, M., Bongartz, A., 2019. Characterization of phenolic compounds and their contribution to sensory properties of olive oil. Molecules 24. https://doi.org/ 10.3390/molecules24112041.

Preedy V, Watson R. 2010. Olives and olive oil in health and disease prevention.

Reboredo-Rodríguez P, González-Barreiro C, Cancho-Grande B, Fregapane G, Salvador MD, Simal-Gándara J. 2015. Characterisation of extra virgin olive oils from Galician autochthonous varieties and their co-crushings with Arbequina and Picual cv. Food Chem. https://doi.org/10.1016/j.foodchem.2014.12.078.

Talhaoui N, Taamalli A, Gómez-Caravaca AM, Fernández-Gutiérrez A, Segura-Carretero A, 2015. Phenolic compounds in olive leaves: Analytical determination, biotic and abiotic influence, and health benefits. Food Res Int 77: 92-108. https://doi.org/10.1016/ j.foodres.2015.09.011.

Tekaya M, Mechri B, Dabbaghi O, et al. 2016. Changes in key photosynthetic parameters of olive trees following soil tillage and wastewater irrigation, modified olive oil quality. Agric Water Manage 178. https://doi.org/10.1016/j.agwat.2016.09.023.

Theodosi S, Kosma IS, Badeka AV. 2021. Quality characteristics of Koroneiki olive oil from Zakynthos Island (Greece) and differentiation depending on the altitude level. Eur Food Res Technol 247: 1235 1248. https://doi.org/10.1007/s00217-021-03705-1.

Tura D, Gigliotti C, Pedò S, Failla O, Bassi D, Serraiocco A. 2007. Influence of cultivar and site of cultivation on levels of lipophilic and hydrophilic antioxidants in virgin olive oils (Olea europaea L.) and correlations with oxidative stability. Sci Hortic. https:// doi.org/10.1016/j.scienta.2006.12.036. 
Youssef O, Mokhtar G, Linda BY, Mokhtar Z. 2014. Characterization and quantification of phenolic compounds of extra-virgin olive oils according to their blending proportions. Afr J Biotechnol. https://doi.org/10.5897/ajb12.1763.

Cite this article as: Tekaya M, Amel MB, Mechri B, Ayadi M, Aouina MBS, Mkada J, Belkhiria H, Guesmi A, Ben Hamadi N, Hammami M, Flamini G, Mezghani MA. 2022. Biochemical characterization of olive oil samples obtained from fruit mixtures and from oil blends of four cultivars grown in Central Tunisia. OCL 29: 5. 